\section{Alferidade, decepção e estigma no ciberespaço: desdobramentos da interação social mediada}

\section{RESUMO}

$\mathrm{O}$ artigo investiga a hipótese de as novas mídias representarem um ambiente a fornecer novos elementos para a interação social que, mesmo não replicando as configurações sociais próprias à interação face a face, não é capaz de eliminar a presença de elementos como alteridade, decepção e estigma. Argumenta-se que a percepção da alteridade no ciberespaço é marcadamente instrumental, uma vez que serve como norteadora para o estabelecimento de relações estigmatizantes.

\section{ABSTRACT}

The paper investigates the hypothesis that new media represent an environment which provides new elements for social interaction. Even without replicating the social configurations proper to face to face interaction, mediated interaction is not able to eliminate the presence of such elements as alterity, deception and stigma. It is argued that the perception of alterity in cyberspace is markedly instrumental, since it serves as a reference to the establishment of stigmatised relations.

\section{PALAVRAS-CHAVE (KEY WORDS)}

- Interação social (social interaction)

- Interação social mediada (social mediated interaction)

- Alteridade, decepção e estigma (alterity, deception and stigma)

\section{HermílioSantos}

Professor do programa de Pós-Graduação em Ciências Sociais da PUCRS

\section{Em torno da interação social}

Para Simmel, o intercâmbio ou troca (exchange) é a forma mais pura e concentrada de todas as formas de interação humana. Embora troca e interação sejam termos passíveis de alguma confusão, em que são tomados um pelo outro, na interação despendemos nossa própria energia, na transmissão da "nossa própria substância", enquanto que a troca não ocorre graças a um objeto anteriormente possuído por uma pessoa, mas "graças ao nosso próprio sentimento sobre um objeto, um sentimento que o outro não possuía anteriormente" (Simmel, 1971: 44). Esse intercâmbio significa que a soma dos valores é maior ao final do que antes de ter sido estabelecida uma relação interativa, o que implica que cada parte dá à outra mais do que cada uma possuía anteriormente (Simmel, id.: 43-44). É fundamental que, nesse processo, seja preservada a singularidade da comunicação daqueles envolvidos no processo de interação. Nesse contexto, singularidade é entendida como a possibilidade que cada indivíduo envolvido em um processo de interação possui para modificar o conteúdo do processo comunicativo, no sentido de que é possível a qualquer um "a transmissão de sua própria substância" (Simmel, 1971, p. 44), o que, segundo Simmel, constitui a natureza mesma da interação.

Herbert Blumer identifica duas formas de interação social, a chamada "interação não-simbólica" e a outra precisamente 
“interação simbólica" (Blumer, 1969:8). A interação não-simbólica ocorre quando se reage diretamente à ação de um outro sem que se interprete tal ação, através de reflexos do corpo, por exemplo. Ao contrário, a interação simbólica implica interpretação dos atos. Este segundo tipo de interação é bastante mais complexo e constitui o fundamento para a abordagem do interacionismo simbólico, que está fundado em três premissas: a de que as pessoas agem em relação ao mundo baseadas no sentido dos elementos com os quais entra em contato (objetos físicos, outras pessoas, categorias de seres humanos, instituições, ideais). $\mathrm{O}$ sentido, porém, não é fornecido pelas coisas mesmas, mas através do processo de interação social. A interação ocorre quando se dá a adoção recíproca de papéis, ou seja, quando dois ou mais indivíduos fazem inferências sobre seus próprios papéis e assumem simbolicamente - não fisicamente o papel do outro, utilizando esse processo enquanto orientação para suas ações (Berlo, 1999, p. 131). Nesse processo interativo, os sentidos das "coisas" com as quais interage são manipulados e modificados por um processo interpretativo adotado pela pessoa na relação com os elementos com os quais a pessoa entra em contato. $\mathrm{O}$ processo interpretativo compreende duas fases distintas: na primeira, a pessoa que age estabelece a si mesma os elementos com os quais tem relação, isto é, a pessoa deve especificar os elementos que gozam de sentido. A segunda fase, após o processo de autocomunicação, a interpretação implica uma manipulação de sentidos, na qual o agente seleciona, reagrupa e transforma os sentidos de acordo com o ponto de vista da situação na qual ele está confrontado e que está relacionado com suas ações (Blumer, 1969, p. 5).

Essa breve referência ao interacionismo simbólico nos permitirá explorar o contexto de interação social mediada, particularmente no que se refere à produção de alteridade e ao estabelecimento de relações marcadas pelo estigma.

\section{Alteridade, decepçãı e estigma no ciberespaço}

Como se dá o processo de interação no ciberespaço? Encontramos uma produção recente apontando os aspectos positivos da criação de uma esfera pública no ciberespaço. É comum observarmos interpretações bastante otimistas a esse respeito, sustentando até que as relações no ciberespaço teriam o poder inclusive de eliminar ou ao menos minimizar as relações estratificadas que temos na interação face a face. Slevin (2000) é um desses autores a sustentar uma visão bastante otimista dos efeitos da Internet na sociedade contemporânea. Jones, por seu lado, argumenta que, ao superar os problemas associados à limitação de tempo e espaço, a Internet é capaz de recriar a comunidade (Jones, 1997, p. 9). Jones sustenta que problemas de ordem moral, política e social são o resultado da falta de comunicação e que otimizando a comunicação muitos desses problemas poderiam ser resolvidos. A Internet seria então uma forma de aprimorar a comunidade (Jones, id: 10). Não há dúvida que o ciberespaço representa no mínimo uma novidade nas formas possíveis de relações e interações sociais. Contudo, as conclusões que postulam a tese de que a Internet representaria de fato uma inovação social, propiciando inclusive a construção de uma esfera pública virtual, carece ainda, ao meu ver, de consistência e evidências empíricas.

Ao contrário do que possa parecer, a constatação de Richard Sennet (1992) de que no mundo contemporâneo estaríamos diante da corrosão da noção de homens públicos não parece estar sendo contradita pela introdução cada vez mais intensa de interações mediadas pelas novas tecnologias de informação e comunicação. Não é exatamente a esfera pública que está sendo incrementada nesse processo, uma vez que a percepção do outro - presente no ciberespaço - é um artifício utilizado mais para a exclusão do que para a inclusão. É fato que novas comunidades se formam no ciberes- 
paço, porém esse novo espaço se aproximaria muito mais de um mosaico de distintas comunidades dispostas a ignorar a existência de outras comunidades do que compartilhar experiências e organizar os esforços a fim de construir uma ágora virtual.

Sugiro que o processo de interação no ciberespaço é possível e marcado profundamente pela percepção da alteridade mesmo quando não resultante de um processo de reflexão sistemática. E é precisamente a percepção de alteridade que antecede e reforça as relações estigmatizantes presentes no ciberespaço. Para Mead (1972), o alter é o grupo organizado de atitudes das respostas dos outros que o indivíduo ("o mesmo") assume enquanto suas. Com isso, a alteridade implicaria a percepção e reconhecimento do outro. Esse reconhecimento não implica, contudo, qualquer indício de mimetismo ou mesmo de aceitação a priori. Assim, a alteridade é um momento indispensável no processo interativo, mas não é garantia de que um tal processo se desenvolva de forma justa, ética ou simétrica, ou seja, de que os sujeitos envolvidos nesse processo se beneficiam igualmente dos dividendos interativos resultantes. A alteridade, ou seja, a relação do eu com o outro, provoca medo, segregação e exclusão (Jovchelovitch, 1998: 69) e não é, portanto, como afirma Jodelet, unicamente o produto de construção social, mas sim "produto de duplo processo de construção e de exclusão social" (Jodelet, 1998: 47). Relativamente ao processo interativo no ciberespaço chamo a atenção precisamente para esse segundo aspecto, ou seja, de que a alteridade no ciberespaço possui um componente indisfarçável de exclusão a partir do estigma.

As formas correntes de interação no ciberespaço, como os diferentes tipos de salas de bate-papo (chat rooms), grupos de discussão e a própria troca de correspondência por meio do correio eletrônico, são possíveis por estarem orientadas por uma percepção da alteridade. As comunidades se afirmam e são possíveis na medida em que há a percepção do eu e do outro, ou seja, a percepção da identidade e da pluralidade. Entretanto, uma tal percepção não está orientada para a integração da pluralidade no processo interativo. Ao contrário, o que está por detrás da construção de comunidades virtuais no ciberespaço é precisamente a tentativa de exclusão da diferença, na medida em que as comunidades não devem ser violadas por "intrusos". Diferente de uma abordagem mais propriamente nostálgica, as comunidades no ciberespaço representam um momento reservado ao convívio com o semelhante e não com o distinto. Mesmo aqueles formatos de salas de bate-papo que dispõem de mais recursos interativos, como é o caso dos chat circles, desenvolvido pelo Media Lab do $\mathrm{MIT}^{1}$, não parecem abrir espaço para o convívio com a diferença. Diferentemente das "salas de bate-papo" tradicionais, os chat circles apresentam uma representação de uma sala, com fundo negro, em que cada presente está representado por uma cor (o nome e um círculo vazio). Ao escrever uma mensagem o círculo se enche com o texto escrito. Procurando reproduzir o ambiente físico, no chat circle a proximidade física dos interlocutores é relevante, uma vez que nem todos os presentes na sala têm acesso visual aos diálogos, mesmo "ouvindo" ruídos da conversação ${ }^{2}$. Entretanto, em comum com as salas tradicionais, nos chat circles a reação à transgressão à expectativa comum é dupla, segue-se ou o estigma ou a decepção.

Originalmente, estigma designava entre os gregos os sinais corporais utilizados para tornar evidente o status moral (de escravo, criminoso, traidor, etc.) de quem os portava (Goffman, 1988, p. 12). Nos dias de hoje, embora o estigma não seja mais evidenciado por marcas físicas, ainda representa o infortúnio vivido por aqueles que por algum motivo não são considerados "normais" em determinada comunidade, ou seja, aqueles que se "afastam negativamente das expectativas particulares" (Goffman, 1988: 14). O conteúdo do estigma, que 
invariavelmente se vincula à discriminação, é diferente de sociedade para sociedade (Abels, 2001,p. 156), ou seja, cada sociedade determina quais as características que serão consideradas socialmente normais.

Uma outra reação comum à transgressão é a decepção. A decepção tem lugar quando, no processo interativo, percebemos uma contradição entre o que um ator assume ser e seus atos subsequentes. A decepção ocorre em razão de percebermos nossos interlocutores não apenas enquanto simples indivíduos, mas enquanto padrões de categorias sociais. Donath, citando Simmel (1971), afirma que nossas primeiras impressões, baseadas numa breve observação, vão determinar as categorias sociais básicas nas quais iremos "catalogar" nosso novo conhecido e com as quais iremos orientar nossa interpretação posterior e mais detalhada das suas motivações e comportamentos (Donath, 2000, p. 49). Quando percebemos alguma contradição na identidade assumida por nosso interlocuto,r e antes que duvidemos de sua identidade, é comum que reinterpretemos seus atos. Apenas quando essa reinterpretação confirma nossa suspeita é que nos decepcionamos. Aqui, é preciso introduzir uma distinção entre decepção e engano. Ao contrário da decepção, o engano ocorre quando identificamos um equívoco - e o assumimos - em nosso procedimento inicial de catalogar nosso interlocutor entre os padrões de categorias sociais. A recomposição das relações após um engano parece ser mais provável que após a decepção.

Nos aplicativos de Internet que permitem uma relação mais interativa, como as salas de bate-papo, identificamos uma orientação bastante particular de como o processo interativo deve se desenrolar. Como afirmado anteriormente, este está orientado mais para a exclusão da diferença do que para criar as condições para o convívio com a diversidade, principalmente por meio da classificação das salas por categorias bastante claras, como por regiões, cidades, idade, sexo, religião, etc. Tais categorias trazem já embutidas nelas o processo de reflexão em torno da alteridade pronto para consumo, ou seja, tais categorizações representariam um atalho para o processo de reflexão da alteridade. É verdade que a representação das identidades individuais no ciberespaço pode ser falsificada com certa facilidade, chegando alguns autores a afirmarem inclusive que ela abriria espaço para o surgimento de múltiplas identidades (Jones, 1997, p. 25). Assim como no relacionamento face a face, ou talvez de forma ainda mais intensa, a identificação da identidade do interlocutor é quase uma obsessão. Praticamente qualquer diálogo nas salas de bate-papo iniciam-se pela tentativa de verificação da identidade do interlocutor, às vezes o diálogo não chega a ultrapassar essa fase, sobretudo quando se descobre se não a verdadeira identidade, pelo menos a tentativa de trapaça identitária. A essa descoberta segue-se então a decepção ou o estigma. As formas mais comuns de decepção dizem respeito ao gênero e à idade (Donath, 2000: 49). É comum que, aquele que provoca a decepção, seja alvo de uma tentativa ativa de estigmatizá-lo, quando é denunciado para os demais presentes na sala. Mesmo que a tentativa de falsificar a identidade não esteja na origem da motivação para o estigma, o estigmatizado encontrará pouca receptividade ou simpatia entre os "normais" para que possa lidar da melhor maneira com a discriminação, já que o processo interativo no ciberespaço é marcadamente orientado pela lógica da eficácia, pois não há tempo para diferentes. Nesse caso, resta ao estigmatizado e ao trapaceiro a alternativa de sair da sala e retornar com outro pseudônimo.

No processo de interação face a face, ao contrário, parece haver um espaço razoável para a recuperação das identidades estigmatizadas. Em seu estudo sobre os rituais de interação, Goffman analisa o trabalho de construção da face (Goffman, 1967). O termo face é definido como os valores que uma pessoa reivindica para si durante o 
contato com outros. Assim, face indica uma imagem do self delineada em termos de atributos socialmente aceitos (Goffman, 1967, p. 5). Nesse sentido, a própria face e a face de outros constituem constructos da mesma ordem, no sentido de que são as regras do grupo que determinam o sentimento e a aceitação das faces envolvidas. Em geral, as pessoas possuidoras de habilidades sociais conhecem - mesmo que não seja um conhecimento sistematizado - o processo de trabalho ou construção da face. Vivemos, no entanto, situações em que nossa face é ameaçada ou deteriorada. Nessas situações podemos ser alvos de estigma por parte dos membros da comunidade da qual fazemos parte, sem que apresentemos características físicas que evidenciam um tal estado. Nem todos, contudo, estão em condições de recompor a face, não apenas em função de uma eventual situação psicológica pouco favorável, mas também pelas condições sociais nas quais estamos submetidos. De acordo com Goffman, os outros membros da comunidade devem assumir um papel destacado na recomposição da face daqueles em situação de face ameaçada. Esse processo pode ser realizado por indivíduos espontaneamente, ou ainda pode ser um trabalho direcionado e consciente. Goffman sugere uma cooperação no trabalho de (re)construção da face ameaçada. Esse processo não parece encontrar um ambiente propício no ciberespaço.

Embora as formas interativas mediadas pela Internet pareçam ser propícias à tentativa de falsificação da identidade, seu sucesso é apenas parcial, uma vez que não é capaz de encobrir os elementos fundamentais caracterizadores da identidade, já que a interação no ciberespaço depende de uma habilidade bastante reveladora: a linguagem escrita. Ao contrário da interação face a face, que depende dos aspectos físicos visíveis e das deixas simbólicas para a fluência do processo interativo, a interação no ciberespaço, ao provocar uma redução do fluxo das deixas simbólicas, fica a depender fundamentalmente da escrita. Sen- do uma das tecnologias mais avançadas à disposição da humanidade (Lévy, 1999,p. 87-90), a escrita revela muito mais que esconde características fundamentais da identidade. Com algum recurso à disposição é possível disfarçar alguns aspectos visíveis da nossa identidade, como por exemplo por meio de um incremento das vestimentas e da maquiagem. Quando o processo interativo passa a depender menos dos aspectos visíveis de características identitárias, esse processo tenderia a depender de maneira mais contundente dos recursos à disposição, como a escrita. Por um lado, a comunicação baseada preponderantemente na escrita permite uma ação comunicativa mais reflexiva, na medida em que esse processo interativo não é necessariamente sincrônico. Ou seja, as respostas podem passar por um processo maior de reflexão, permitindo assim que aqueles que não dispõem de habilidades retóricas bem desenvolvidas possam igualmente colocar-se sem maiores prejuízos no processo interativo. Por outro lado, com a eliminação ou ao menos a minimização da relevância das outras características identitárias que não a linguagem escrita, o processo interativo fica a depender unicamente da habilidade de argumentação escrita. Trata-se evidentemente de uma limitação, cujos elementos de segregação estão bastante presentes. $\mathrm{O}$ elemento segregador não reside no fato de fazer uso intensivo da escrita, mas sim da quase exclusividade da dependência desse recurso interativo.

\section{Conclusão}

Discutimos nesse artigo alguns aspectos da interação social mediada, dando atenção especial ao papel da alteridade e à presença da decepção e do estigma nesse processo. Partimos precisamente da interação face a face, uma vez que, mesmo introduzindo novos elementos à interação social, é essa modalidade interativa que do ponto de vista analítico e empírico poderá nos ajudar a 
compreender melhor as eventuais mutações das formas de sociabilidade. Argumentou-se que o processo de interação no ciberespaço é possível e marcado profundamente pela percepção da alteridade mesmo quando não resultante de um processo de reflexão sistemática. E é precisamente a percepção de alteridade que antecede e reforça as relações estigmatizantes presentes no ciberespaço •

\section{Notas}

1 Os chat circles foram desenvolvidos inicialmente pela brasileira Fernanda Viegas.

2 Mesmo aqueles posicionados distantes uns dos outros podem visualizar a presença de todos na sala, mas não conseguem visualizar as frases, apenas que os círculos se enchem quando os interlocutores se falam. Para participar do diálogo, é preciso estar "fisicamente" próximo do interlocutor. Aqueles que não querem ser invadidos em seu diálogo, apenas se afastam com o mouse para um outro canto da sala.

\section{Referências}

ABELS, Heinz. Interaktion, Identitüt, Präsentation - Kleine Einführung in interpretative Theorien der Soziologie. Wiesbaden: Westdeutscher Verlag, 2001.

BERLO, David K. O processo da comunicação - introdução à teoria e à prática. São Paulo: Martins Fontes, 1999.

BLUMER, Herbert. Symbolic interactionism - perspective and method. Englewood Cliffs: Prentice-Hall, 1969.

DONATH, Judith S. "Identity and deception in the virtual community", In: Communities in cyberspace, Marc A. Smith/Peter Kollock (eds.). London: Routledge, 2000.

GOFFMAN, Erving. Estigma - Notas sobre a manipulação da identidade deteriorada. Rio de Janeiro: LTC, 1988.

GOFFMAN, Erving. Interaction ritual. New York: Anchor Books, 1967.

JODELET, Denise. "A alteridade como produto e processo psicossocial", in: Angela Arruda (org.), Representando a alteridade. Petrópolis: Vozes, 1998.

JONES, Steven G. "The internet and its social landscape", in: Steven Jones (org.), Virtual culture - Identity and communication in cybersociety. London: Sage, 1997.

JOVCHELOVITCH, Sandra. "Re(des)cobrindo o outro Para um entendimento da alteridade na teoria das representações sociais", in: Angela Arruda (org.), Representando a alteridade. Petrópolis: Vozes, 1998.

LÉVY, Pierre. As tecnologias da inteligência. São Paulo: Editora 34, 1999.

MEAD, Georg H. Mind, self and society. Chicago: University of Chicago Press, 1972.

SENNET, Richard. The fall of public man. New York: W.W. Norton, 1992.

SIMMEL, Georg. On individuality and social forms, editado por D. Levine. Chicago: The University of Chicago Press, 1971.

SLEVIN, James. The internet and society. Cambridge: Polity Press, 2000. 